\title{
A Faculty-Librarian Collaboration in the Undergraduate and Graduate Degree Project and Thesis Preparation Courses
}

\author{
CATHRYN COPPER \\ Woodbury University
}

\begin{abstract}
This paper discusses the insertion of information literacy at arguably the most critical point in the academic curriculum. Central to the discussion are practical aspects such as the formation of the faculty-librarian co-teaching relationship, the logistics and process of co-teaching, and qualitative and quantitative benefits to student academic achievements and library resources and services. Results of the experience focus on assessment of the co-teaching model and the benefits of collaboration in architecture education.
\end{abstract}

\section{INTRODUCTION TO THE DISCUSSION}

It is an ethical imperative that architecture curriculums equip students with the skills to tackle the rapidly changing information landscape we face today. With information easily accessible, students and professionals alike are faced with ethical dilemmas about how to find and use accurate and reliable information. ${ }^{1}$ As a result, information literacy skills are increasingly important, and this paper lays the foundation for how the faculty-librarian co-teaching model can be used to enhance student information literacy skills. Furthermore, the research in this paper reveals that when librarians extend their presence beyond the physical boundaries of the library, there are direct qualitative and quantitative benefits to student academic achievements and library resources and services. Also referred to as embedded librarianship, faculty-library co-teaching is an effective tool to extend information literacy services outside the library and reach users at their point-of-need. ${ }^{2}$ Dane Ward's commentary in The Chronicle of Higher Education petitions libraries to act as institutional hubs, ideally suited to form and advance relationships that allow librarians to insert their skills at the point-of-need and engage with patrons resulting in more informed, well-equipped students. ${ }^{3}$

\section{ABOUT WOODBURY UNIVERSITY AND THE BRANCH LIBRARY}

Woodbury University, located in Southern California, is a nonprofit, private institution founded in 1884 with a thriving reputation as a top architecture and design school. The undergraduate architecture program continues to gain national traction and was ranked $18^{\text {th }}$ in the 2018 Design Intelligence survey. With a total student population of just over 1,100 , the University is ideally suited and strives to focus on the student experience.

The School of Architecture opened a satellite campus in San Diego, California in 1998. Today the satellite campus makes up about one-fifth of the School of Architecture. The small population and autonomy from the main library allows the branch library to operate as an incubator of ideas and initiatives, and easily experiment with its services. One such experiment, was the librarian co-teaching the architecture undergraduate degree project and graduate thesis preparation courses during Fall 2016.

The branch library is supported financially by both the main library and the School of Architecture, while the branch library is overseen by the main library it also indirectly reports to the School of Architecture. Furthermore, within the School of Architecture, the branch librarian attends faculty meetings and is appointed to committees. This dual reporting structure strengthens the librarian's position in becoming embedded in the curriculum. ${ }^{4}$

Being embedded in the School of Architecture gives the librarian the opportunity to design instruction for the specific environment he or she serves. ${ }^{5}$ The branch librarian teaches a required information literacy course and offers in-class bibliographic instruction. However, compared to the main library, one-shot instruction sessions are not as frequently requested. Susan L. Hall and Derek Hunter Marshall confirm that one-shot overviews of detailed database search functions are less in demand at branch libraries. ${ }^{6}$ The smaller student populations and more personalized-services often make one-shot instruction sessions at branch libraries cumbersome. The formal structure and occasional repetitiveness is awkward for faculty and students who are accustomed to one-on-one instruction. Furthermore, the practice-based learning and studio culture at architecture schools provide unique opportunities to develop customized approaches to instruction that engage and interest architecture students. ${ }^{7}$

\section{FORMATION OF THE CO-TEACHING ROLE}

The role of co-teacher is the result of knowledge and trust building during the librarian's six-year tenure embedded in the School of Architecture. Research shows that liaison work enhances subject expertise and leads to an increase in confidence from teaching faculty, nevertheless building the trust of faculty is a slow process. ${ }^{8}$ Essentially, three elements needed to be in effect to make co-teaching a reality. First, the physical location of the branch library in the School of Architecture is beneficial to developing relationships with academic faculty. ${ }^{9}$ Second, building a knowledge base in the discipline and the curriculum is essential to becoming 
embedded. ${ }^{10}$ Last, librarians need to clearly communicate an interest in teaching at the advanced research level.

The San Diego campus wanted to test research that shows a collaborative approach builds more critical, reflective thinkers. ${ }^{11}$ Talitha R. Martlin and Allison Carr agree that incorporating a librarian in an architecture course offers a fresh look at the curriculum. ${ }^{12}$ The divergent expertise of a librarian from architecture faculty is imperative to the pedagogical method. The faculty-librarian co-teaching model is rooted in the dual strengths, unlike the model of a solo architecture faculty encouraging strong bibliographic resources. The coteaching across disciplines approach provides the librarian an equal opportunity to engage information literacy concepts deep into the architecture curriculum.

\section{PROFESSIONAL PRACTICE II AND CRITICISM 4}

On account of the small student population, the undergraduate degree project and graduate thesis preparations courses were cross-listed during Fall 2016. The two courses were ARCH 448 Professional Practice Research and $\mathrm{ARCH}$ 648 Criticism 4 Architecture Research Salon and Thesis Preparation. The central learning outcome for both courses is to develop an architectural research argument and methodology. Additional learning outcomes include: propose a research agenda, analyze a set of project constraints, and verbally and visually articulate the ways in which a theoretical intention can translate into architecture.

As a co-instructor, the librarian participates in the course on an ongoing basis teaching information literacy skills. ${ }^{13}$ The other co-instructor, Associate Professor Jose Parral, co-taught the course previously, though never with a nonarchitecture faculty member. Based on his prior experience, he suggested three formats for co-teaching: the two instructors could alternate lectures, one instructor could take the lead, or, the most optimal and chosen approach, the instructors would integrate their expertise into comprehensive lectures. It is important for the librarian to be involved in all aspects of the thesis preparation course so that she can follow the students' research trajectories and accurately assess their progress. Lijuan Xu and Nestor Gil used the same format to co-teach an art studio. Their experience confirms that it allowed the librarian to address research-related questions and needs as they came up and follow student's progress. ${ }^{14}$ In addition, the intense involvement gives the librarian more opportunities to offer needs-based services, understand the culture and research habits of the students, and form a strong partnership with the co-teaching faculty member. ${ }^{15}$ Matlin and Carr confirm the effectiveness of this approach by stating that the literature on co-teaching emphasizes the importance of having both instructors present during all class sessions. ${ }^{16}$

The design of the course and content development materialized through weekly discussions between the co-instructors the summer prior to the fall semester. The instructors worked seamlessly together both attuned to the other's expertise and open to new approaches. The first half of the course was dedicated to exploring interests and developing research techniques. Lectures addressed information literacy topics such as managing research resources, critically analyzing articles, developing research questions, developing a thesis statement, constructing an argument, supporting claims with evidence, contributing original research, and the CATTt methodology. ${ }^{17}$

Assignments were writing intensive and progressively guided the students toward developing a research topic and growing bibliographic content. The final assignment was the creation of a book that also functioned as a design object. The lectures and assignments were designed so that students increasingly became familiar with four of the six frames from the ACRL Framework for Information Literacy. The frames covered were information creation as a process, research as inquiry, scholarship as conversation, and searching as strategic exploration. ${ }^{18}$ The course content led students on an exploration of these concepts, not only through the research process, but more importantly first-hand through the creation of their book. Ultimately the frames helped to explain that a thesis is a response to a particular topic or issue and the proposed solution is a representation of built work. ${ }^{19}$

The second half of the course was formatted similar to a studio course. At that point in the semester, the students' topics and research were individualized and instruction needed to be personalized in order to help them progress. The instructors jointly met with each student on a weekly basis. The weekly meetings allowed the librarian to reinforce the framework holistically at the point-of-need, rather than through a forced agenda. This approach was well-received by students evident by their engagement. Similar to Helms and Whitesell, the librarian was able to perceive unspoken research needs and implement solutions specific to each student. ${ }^{20}$ David Shumaker confirms that a successful embedded librarian is "one who can identify the need, the sources, and the value of information-often before the customer/colleague thinks of it-and deliver what's needed." ${ }^{21}$ The personalization of content delivery in weekly meetings was significantly beneficial to both the students and instructors.

\section{QUANTITATIVE AND QUALITATIVE IMPACTS ON LIBRARY RESOURCES AND SERVICES}

Library statistics at the branch library show that the librarian teaching at the advanced research level triggered an increase in use of library resources and services. The increase is especially impressive in an architecture school where research indicates students are among the most difficult to attract to the library since they often see library research as irrelevant to and incompatible with creative production. ${ }^{22}$ However, the benefits of observing student research behavior and working 
closely with a faculty member improved the librarian's knowledge about architecture and architectural education, and ultimately resulted in a better perception of the library. ${ }^{23}$

Circulation and interlibrary loan statistics more than doubled during the semester that the librarian co-taught. Circulation during the 2016-2017 academic year saw a 9\% increase over the 2015-2016 academic year. Particularly in Fall 2016, 7.3 items circulated for every one fulltime student, compared to 3.4 items the prior fall semester. Interlibrary loan requests suggest an even greater surge in library usage. Compared to the previous fall semester, the number of interlibrary loan requests increased by $300 \%$, and $67 \%$ of those requests were from students in the degree project and thesis courses. Thus, the pedagogical model implemented had a positive impact on library resources and services. These numbers are now being used to protect and build the library budget, which in return continues to provide resources and services that aid in faculty professional development. Therefore, the impact is widespread and benefits more than student success.

Perhaps the longest lasting impact from co-teaching came in the form of collection development. Development of a useful collection is important in any library setting, but especially critical in a branch setting when constituents expect a tailored experience. Hall and Marshall state, "Building and managing the collection to reflect current needs is one of the most important aspects of branch work. The greater understanding of the academic program, faculty interests and course offerings, the better the potential for being effectively embedded." ${ }^{24}$ The direct experience the librarian had with students at the advanced research level led to more informed collection development decisions. Students commented on the valuable additions to the collection, resulting in a more positive perception of the library. With a more profound understanding of student research needs, the collection better serves the immediate research needs of the degree project and thesis students, as well as future students and faculty.

Qualitatively, the data collected during the co-taught semester indicates a positive increase in the perception of library resources and services. The focused attention at the oneto-one level resulted in a surge of library usage and denotes an encouraging development on the level of research in the course. Thus, presumably, the faculty-librarian co-teaching model increased the academic rigor of the course, and quantitative analysis in the assessment phase supports this argument.

\section{ASSESSMENT OF THE CO-TEACHING MODEL}

Assessing the faculty-librarian co-teaching model was a multi-step process that involved evaluating course grades, student feedback, mid-term and final reviews, and University-wide learning outcomes. Although some research shows that co-teaching produces no significant difference in student achievement, ${ }^{25}$ course grades for ARCH 448 actually improved. The average final course grade was one letter grade higher than the previous two cohorts. While this is not a completely equivalent comparison since the instructor, students, assignments, and rubrics were different, it indicates that the librarian co-teaching had a positive impact on student achievement. Helms and Whitesell's research supports improved course grades. Research instruction by the librarians at Dalton State College aided in an overall improvement of grades, the number of students receiving a $B$ grade or above increased by $134 \%$ when a librarian was engaged in the capstone course. ${ }^{26}$ Going forward, a longitudinal study and pre-course and post-course surveys would help reinforce the argument that the faculty-librarian co-teaching model improves student achievement.

During the following semester, when students are expected to translate their research into representations of built work, students continued to engage with the library and librarian. Building relationships with the students during the fall semester led to more involvement from the librarian during the design phase. Lynn Silipigni Connaway confirms the importance of building relationships during instruction sessions, implying these relationships lead to new methods for users to interact with their librarians. ${ }^{27}$ One new method of interaction was that the librarian served as a juror for mid-term and final reviews. Xu and Gil explain that students value the presence of librarians and find them helpful in the development of their creative projects. ${ }^{28}$ The impact the librarian had on the design phase is unclear, but anecdotal evidence suggests that in final presentations students focused more on their research trajectories than their design decisions, and jurors found the research questions captivating but wanted more architectural conclusions. Regardless, the continued engagement of the librarian from faculty and students during the design phase is a direct reflection of the value and trust built during the previous semester.

A deeper assessment was completed in coordination with the University's upcoming WASC accreditation visit. As one of the writing intensive courses in the architecture department, the instructors of ARCH 448 evaluated the student's proficiency level in written communication, one of the WASC five core competencies. The instructors graded the final course assignment using the written communication rubric that was developed by faculty at the University. Based on the findings, students in the co-taught course were found to be proficient in the "Research, Sources, and Evidence" category, meaning that most sources used were credible and relevant (in scope and currency) and aided in the development of ideas. On the other hand, students fell short in the "Content Development" category. The majority of students used appropriate, relevant, and compelling content to explore ideas, demonstrated a clear understanding of the 
subject matter, and communicated multiple perspectives on the subject. However, when analyzing the resources there was minimal critical thinking and conclusions drawn. Xu and Gil had a similar experience in the co-taught art studio, sharing that students used quality sources, but the conclusions were broad and not critical. ${ }^{29}$

Thus, the biggest challenge identified at Woodbury was that one semester is not an adequate amount of time to cover the syntax of a research argument and content development. While a semester may be considered a luxury compared to institutions on the quarter system, it still does not accommodate the flexibility needed for simultaneous information literacy instruction. In one semester, students were able to locate sources, but were challenged when it came to synthesizing the information and constructing an argument. The typical academic structure does not support the need for information literacy inserted into the curriculum even though the literature consistently indicates positive results when a librarian is embedded in instruction. The embedded model at Woodbury suggests even co-teaching at the advanced research level does not go far enough to integrate information literacy concepts. On the other hand, what it does indicate is that there is greater need for information literacy instruction than what is being served through traditional one-shots and isolated information literacy courses. The instructors believe that if students were exposed earlier and more consistently to information literacy instruction in the curriculum, then the ARCH 448 and ARCH 648 courses could focus on content development.

During the assessment phase, Parral stated, "Having the librarian as co-teacher model helped tremendously in relation to not only mechanics of the written work and research, but more importantly providing a broader, more appropriate approach to the method of constructing a thesis," and emphasized that co-teaching should happen in more classes and earlier in the curriculum. Similar to Xu and Gil's experience, even though the architecture faculty member had to give up time to cover information literacy content, it was evident that embedding a librarian resulted in richer research questions and more scholarly investigations. ${ }^{30}$ The branch librarian has minimal interaction with students between first year and fifth year. The isolated information literacy course that librarians often teach is an introduction to information literacy concepts and operates as a stand-alone course. The divorced model makes it difficult for students to connect the learned concepts to courses in their discipline. If information literacy concepts were engrained more consistently throughout the curriculum, then the development of an architectural thesis could take precedent in the degree project and thesis courses. Helms and Whitesell confirm that embedding a librarian earlier would improve senior-level courses and student research skills. ${ }^{31}$ What the assessment suggests is that the librarian-faculty co-teaching model had a positive impact on student achievement but in order for the students to become totally information literate and better critical thinkers the librarian needs to be systematically embedded throughout the curricular map.

\section{THE SCAFFOLD MODEL}

In comparison, Kansas State University has implemented a robust embedded librarian model in their Master of Landscape Architecture Program that consists of two librarians scaffold throughout the curriculum. ${ }^{32}$ The librarian's participation is encouraged in all lectures, critiques, meetings, site visits, and reviews during all five years of the program. In first year courses, the librarians discuss foundational concepts like using the library and intellectual property. An assessment is conducted in year two so that the librarians' understanding of what students prefer and value evolves. As the students advance through the curriculum, information literacy instruction becomes more tailored. In years two and three, students are taught how to slow down the research process and critique resources. By years four and five the librarians co-teach courses, serving as mentors rather than instructors. Individual consultations at the graduate-research level help students with literature reviews, writing, and the academic rigor of proposals. ${ }^{33}$

The result of the scaffold model are librarians that map their subject expertise throughout the curriculum, allowing them to make more meaningful contributions to the students, faculty, and school. Since implementation of the scaffold model, the librarians at Kansas State University have partnered with faculty on publications, college-wide instruction, and exhibitions. ${ }^{34}$ Most importantly, in comparison to the co-teaching model implemented at Woodbury, the scaffold model inserts information literacy concepts at the point-of-need and are gradually reinforced as the student progresses, thus marrying information literacy to the architecture and design process. Therefore, if a variation of this model is implemented, students will be more well versed in synthesizing information and constructing an argument prior to degree project and thesis preparation courses.

\section{CONCLUSIONS ON THE DISCUSSION AND FUTURE RESEARCH}

The student experience is enriched by combining expertise in the classroom. Being in the classroom or studio allows librarians to engage with students at a micro level. From Xu and Gil's co-teaching experience they declared, "The librarian's presence outside the library helps personalize library services and increase the connection of libraries and their resources to the student's creative work." ${ }^{35}$ With more personalized services, architecture education is enhanced, and at Woodbury an increase in academic rigor was noted.

In conclusion, the findings show that formally engaging a librarian in degree project and thesis preparation courses had 
an overall positive impact. No adverse effects were observed. The allocation of time spent in the classroom on information literacy concepts resulted in an increase in library usage, together with, a more academic pursuit of architectural investigations. It is highly recommended that architecture faculty incorporate library instruction at all levels of the curriculum, and when applicable, use librarians as co-teachers for a more personalized instruction approach. Faculty and librarians alike need to be advocates for collaborative instruction that give students insight into their queries from multiple perspectives.

Future research would benefit from a longitudinal study that measures student knowledge before and after information literacy instruction at the advanced research level. Likewise, assessment across several cohorts is needed to provide concrete evidence that faculty-librarian co-taught courses increase the academic rigor of degree projects and theses.
22

23 Building on Instructional Synergies," Public Services Quarterly 6, (2010): 225-36.

24 Hall and Marshall, "Embedded Librarianship in Branch Settings," 508-514.

25 Matlin and Carr, "Just the Two of Us," 61-72.

26 Helms and Whitesell, "Transitioning to the Embedded Librarian Model," 401-413.

27 Connaway, “Chapter Twelve," 83-88.

28 Xu and Gil, "Librarians as Co-Teachers," 122-136.

29 Ibid.

30 Ibid.

31 Helms and Whitesell, "Transitioning to the Embedded Librarian Model," 401-413.

32 Thomas M. Bell and Ellen Urton, "Design/Build: Embedded Librarians Create Connections from $1^{\text {st }}$ Year to Master's Reports in the APDesign Curriculum" (presentation, Annual Conference of the Association of Architecture School Librarians, Seattle, WA, March 11-13, 2016).

33 Ibid.

34 Ibid.

35 Xu and Gil, "Librarians as Co-Teachers," 122-136.

\section{ENDNOTES}

1 Lynn Silipigni Connaway, “Chapter Twelve," in Library 2020: Today's Leading Visionaries Describe Tomorrow's Library, ed. Joseph Janes (Lanham, Maryland: Scarecrow Press, Inc., 2013), 83-88.

2 Lijuan Xu and Nestor Gil, "Librarians as Co-Teachers and Curators: Integrating Information Literacy in a Studio Art Course at a Liberal Arts College," Art Documentation: Journal of the Art Libraries Society of North America 36, no. 1 (2017): 122-136.

3 Dane Ward, "Envisioning the Fully Integrated Library," The Chronicle of Higher Education, (2017), http://www.chronicle.com/article/ Envisioning-the-Fully/238897.

4 Susan L. Hall and Derek Hunter Marshall, "Embedded Librarianship in Branch Settings: Customizing Liaison Services," New Library World 115, no. 11/12 (2014): 508-514

5 Ibid.

6 Ibid.

7 Ibid.

8 Ibid.

9 Heather Saunders and Ryan W. Taylor, "The Art and Environment of Embedded Librarianship," College \& Undergraduate Libraries 21 no. 2 (2014): 145-154.

10 Hall and Marshall, "Embedded Librarianship in Branch Settings," 508-514.

11 Ward, "Envisioning a Fully Integrated Library," http://www.chronicle.com/ article/Envisioning-the-Fully/238897.

12 Talitha R. Matlin and Allison Carr, "Just the Two of Us: Those Who Co-Teach, Co-Learn," Collaborative Librarianship 6, no. 2 (2014): 61-72.

13 Saunders and Taylor, "The Art and Environment," 145-154.

14 Xu and Gil, "Librarians as Co-Teachers," 122-136.

15 Marilyn M. Helms and Melissa Whitesell, "Transitioning to the Embedded Librarian Model and Improving the Senior Capstone Business Strategy Course," The Journal of Academic Librarianship 39, (2013): 401-413.

16 Matlin and Carr, "Just the Two of Us," 61-72.

17 Cathryn Copper, "CATTt: An Anti-Method for Architectural Research," ACSA News, 2016, http://www.acsa-arch.org/acsa-news/read/read-more/acsanews/2016/07/14/cattt-an-anti-method-for-architectural-research.

18 "Framework for Information Literacy for Higher Education," Association of College and Research Libraries, 2016, http://www.ala.org/acrl/standards/ ilframework.

19 Xu and Gil, "Librarians as Co-Teachers," 122-136.

20 Helms and Whitesell, "Transitioning to the Embedded Librarian Model," 401-413.

21 David Shumaker, "A Response to Embedded Librarianship: A Critical Perspective by Robert Farrell," The Embedded Librarian (blog), May 27, 2016, https:// embeddedlibrarian.com/2016/05/27/a-response-to-embedded-librarianshipa-critical-perspective-by-robert-farrell/. 